\title{
Negative ions detection in air using nano field-effect-transistor (nanoFET)
}

\author{
Yeong-Tai Seo ${ }^{1,2}$, Kook-Nyung Lee ${ }^{1 *}$, Kuk Jin Jang ${ }^{1}$, Min-Ho Lee ${ }^{1}$, HyungSu Lee ${ }^{1}$, WooKyeong Seong ${ }^{1}$ \\ and Yong-Kweon Kim ${ }^{2 *}$
}

\begin{abstract}
We firstly demonstrated the detection of anions in air using a nano field-effect transistor (nanoFET) device. Negative ions in air charged the top surface of the silicon nanoFET channel affecting the fieldeffect and making a conductance change of the channel proportional to anion concentration around the nano channel sensing surface. The real-time detection of anions in air with the nanoFET was performed for various anion concentrations which were differentiated by the distance of the anion generator to the nanoFET sensor. The air anions detection characteristics of the nanoFET device were evaluated with sensitivity and conductance change rates analysis.
\end{abstract}

Keywords: Negative ions in air; Air anion detection; NanoFET; Quantitative detection of anions; Semiconductor sensor; Negative ion sensor

\section{Introduction}

Negative ions in air are of great interest for the benefits for air purification and the positive effect on air conditions for healthy living [1-4]. Recently, a number of consumer products utilizing ion-generating technology have become available to eliminate airborne pollutants, such as dust or cigarette smoke, allergens and viruses from immediate breathing spaces [5,6]. These devices work by generating a flow of negative ions that charge and bind together with airborne particulate matter. The charged matter gathers together and precipitates out of the air. In addition to eliminating harmful particulates from the air, negative ions also have a number of unique health benefits [7-9]. A growing number of people are using personal and home air filtration products that generate negative ions to charge and remove airborne particulate matter to create localized zones of improved air quality [10-12].

Various devices exist to detect ions in the air. Some notable examples include the Geiger-Muller tube based radiation detector and parallel plate- or cylindrical platebased electrostatic type detector [13-15]. These air ion counter devices are complicated systems that are much

\footnotetext{
* Correspondence: plummyk@gmail.com; yongkkim@snu.ac.kr ${ }^{1}$ Medical IT Convergence Research Center, Korea Electronics Technology Institute (KETI), \#68, Yatap-dong, Bundan-gu, Seongnam-si, Gyeonggi-do $463-816$, Korea
${ }^{2}$ School of Electrical Engineering and Computer Science, Seoul National 463-816, Korea
${ }^{2}$ School of Electrical Engineering and Computer Science, Seoul National University, Seoul, Korea
}

\section{兽 Springer}

larger and expensive when compared to most ion generating devices. For instance, the electrostatic type detector has an additional fan to create an intake of air to the electrode plate detector. In this paper, we propose an airborne anion detecting sensor using nanoFETs which enables the realization of a very small and low cost air ion detecting device. Semiconductor based airborne ion sensors can be incorporated into consumer electronics allowing for applications such as the performance monitoring of anion generating device often found in air cleaning units today. We fabricated a nanoFET device and evaluated the air anion detection characteristics of the nanoFET sensor device. We measured the real-time conductance change and response properties of the nanoFET when exposed to different anion concentrations in air generated by an air ionizer. Our results demonstrate the possibility of an application of the nanoFET as a negative ion sensor.

\section{Findings}

The nanoFET sensor for the anion detection in air was designed and fabricated with 8 -inch semiconducting process facilities. The FET channel of the device has a similar structure to that of a nanoFET based biosensor $[16,17]$. Figure 1(a) shows the cross-section of the nanoFET device. The handle silicon substrate is used for a universal bottom gate electrode $\left(\mathrm{V}_{\mathrm{bg}}\right)$. A nanoFET has a $20 \mathrm{~nm}$-thick silicon channel and a $5 \mathrm{~nm}$-thick 
gate oxide layer of $\mathrm{SiO}_{2}$ for adsorption of negative ions. The buried oxide (BOX) layer and handle silicon substrate were $145 \mathrm{~nm}$ and $725 \mu \mathrm{m}$ in thickness, respectively. The passivation layer is $1 \mu \mathrm{m}$ of photoresist. Figure 1(b) shows the fabrication process of the device. Starting with a thin SOI (silicon on insulator) substrate (SOI tech, France), the $20 \mathrm{~nm}$-thick silicon nano channel is thinned through thermal oxidation from its initial top layer thickness of 70 $\mathrm{nm}$. The thickness uniformity of nano silicon-channel obtained by the thermal oxidation thinning process was within $6 \%$ of the targeted $20 \mathrm{~nm}$ in the 8 -inch wafer. The nano channel for sensing is defined as an area of $5 \mu \mathrm{m} \times 5$ $\mu \mathrm{m}$ in length and width by a stepper photolithography process as shown in process (ii) of Figure 1(b). In the process (iv) of Figure 1(b), the contact doping implantation was performed with a condition of boron, dose $=5 \mathrm{E} 15$ and

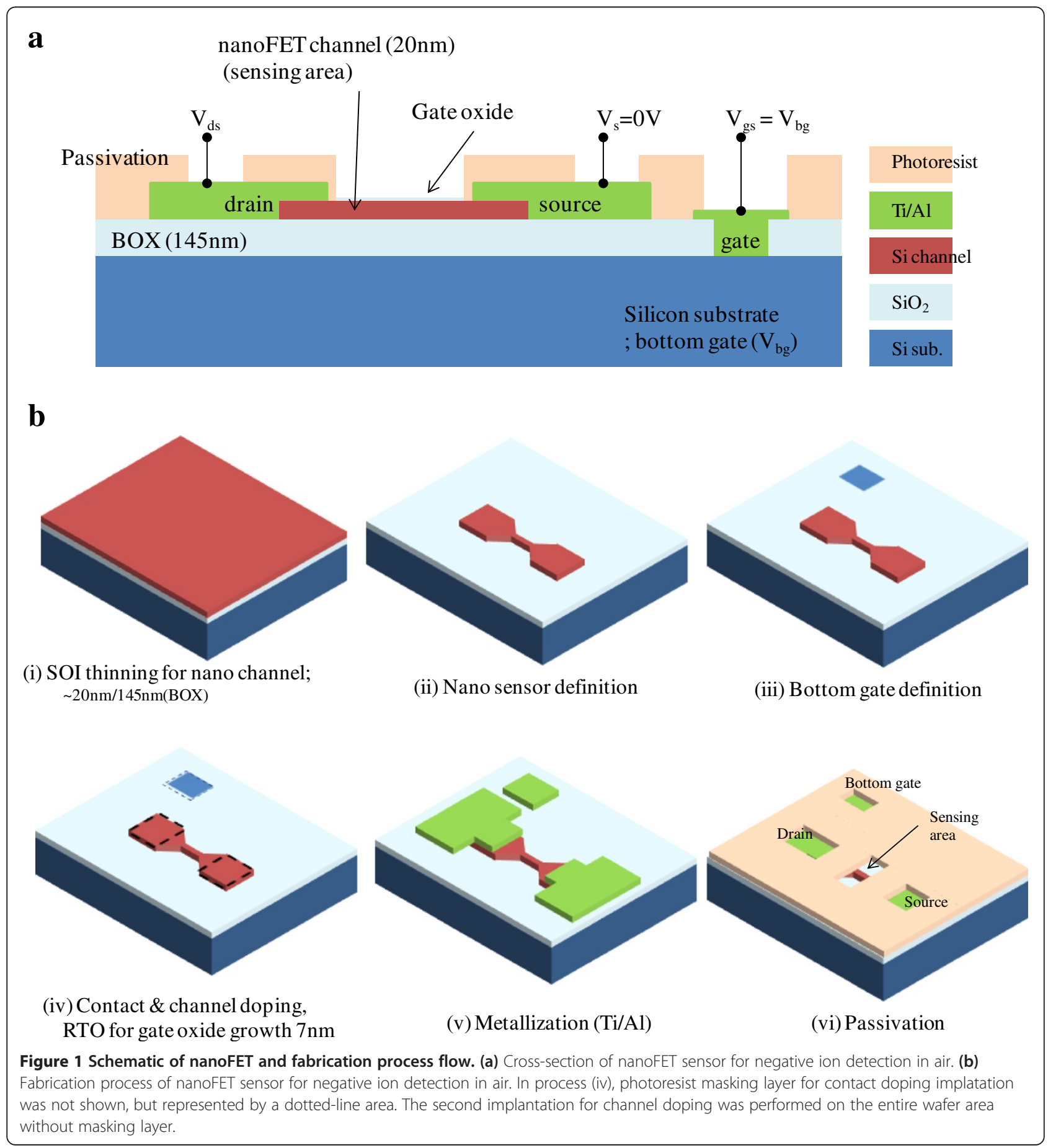


$\mathrm{E}=3 \mathrm{keV}$ in the dotted-line areas with a photoresist masking. After removal of the photoresist, a second implantation for channel doping was followed in the whole wafer area with a condition of boron, dose $=5 \mathrm{E} 12$ and $\mathrm{E}=3 \mathrm{keV}$. The contact doping implantation process was followed by rapid thermal oxidation (RTO) for implantation annealing and gate oxide formation. The thickness of gate oxide obtained by RTO process was within the range of 47 to $53 \AA$ for the $50 \AA$ target thickness. Ti/Al metallization was applied for electrical interconnection with outer circuits. Finally, a photoresist layer $1 \mu \mathrm{m}$ was formed to protect the entire area of the device except the sensing area and electrical pads. The 8-inch SOI silicon process was performed at the facilities of the National Institute for Nanomaterials Technology (NINT, Korea) and the boron implantation process was performed at the National Nanofabrication Center (NNFC, Korea). Figure 2(a) shows the field emission scanning electron microscope (FESEM) image of the fabricated.

Figure 2(b) depicts the experimental scheme to measure and evaluate the properties of the nanoFET sensor for the detection of anions in air. The ion generator used for the experiment was a commercially available air ionizer (Dr. USB, IMH Co. Korea) which consists of a small blowing fan and tip electrodes for air ionization through the arc discharge method [18]. The nanoFET device is placed in a normal direction to the ionized air flow. The concentrations of generated negative ions in the air could be modulated with the distance between the sensor device and the ion generator. A fan in the generator allows the generated negative ions to spread and reach the nanoFET sensor. Figure 3 shows the current $\left(\mathrm{I}_{\mathrm{ds}}\right)$ versus voltage $\left(\mathrm{V}_{\mathrm{gs}}\right)$ characteristics of the fabricated nanoFET device obtained by the sweep of $\mathrm{I}_{\mathrm{ds}}$ $\mathrm{V}_{\mathrm{bg}}$ in the forward and backward direction. We compared the initial fabricated state (rectangular dotted line), the charged state due to negative ions exposure(Xlabeled dotted line) and the steady state after a duration of time had passed with the ionizer off (triangular dotted line). The $I_{d s}-V_{b g}$ recording shows properties of high performance p-type FET through backgate modulation of $\mathrm{V}_{\mathrm{bg}}$ from $-20 \mathrm{~V}$ to $+20 \mathrm{~V}$ at a constant $\mathrm{V}_{\mathrm{ds}}$ of $1 \mathrm{~V}$. The measurement had results of an $\mathrm{I}_{\text {on }} / \mathrm{I}_{\text {off }}$ ratio over $10^{7}$ and a transconductance $\left(\mathrm{g}_{\mathrm{m}}\right)$ of $1.05 \mu \mathrm{S}$. When the channel surface of the nanoFET device was charged by the negative ions in air, the I-V curve moved in the right-upper direction as shown in the $\mathrm{X}$-labeled dotted line $\mathrm{I}_{\mathrm{ds}}-\mathrm{V}_{\mathrm{gs}}$ graph. The shift corresponds to the quantities of negative charges on the channel surface. It was reasonable to conclude that negative ions may be adsorbed on the surface of the FET channel when the negative ion concentration in the air increased around the nanoFET sensor during operation of the air ionizer. After the ion generator was turned off, the I-V curve moved in a recovering direction to the initial state of the device as shown in the triangular-shaped marker a



b



Figure 2 The fabricated nanoFET device and experimental set-up for negative ions detection in air. (a) A FESEM photograph of the fabricated device. (b) Experimental setup for ion detection consisting of ionizer and nanoFET ion sensor device.

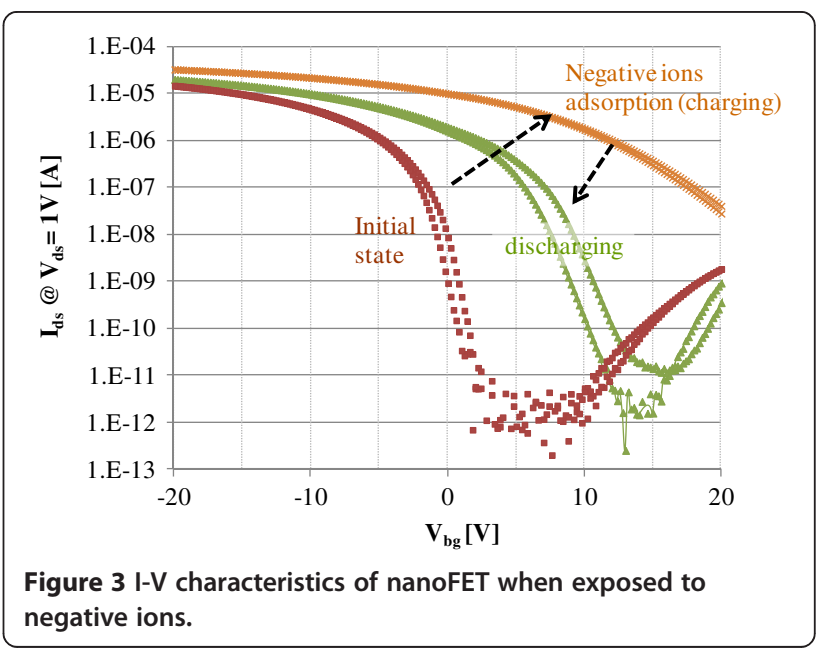


graph due to a reduction of adsorbed charged ions caused by charge leakage. It was noted, however that it did not recover completely to the initial state. Figure 4(a) and (b) show the real-time measurement of nanoFET response to the negative ions in the air. The drain-source current $\left(\mathrm{I}_{\mathrm{ds}}\right)$ at a constant drain-source voltage $\left(\mathrm{V}_{\mathrm{ds}}=0.1 \mathrm{~V}\right)$ increases according to the back-gate voltage $\left(\mathrm{V}_{\mathrm{bg}}\right)$ modulation from $0 \mathrm{~V}$ to $-15 \mathrm{~V}$ in $-5 \mathrm{~V}$ increments which representative of typical p-type channel FET properties. The ionizer was turned on at $\mathrm{t}=200 \mathrm{sec}$ with $\mathrm{V}_{\mathrm{bg}}=0 \mathrm{~V}$. $\mathrm{I}_{\mathrm{ds}}$ increased gradually and eventually saturated as shown in Figure 4(a). This was indicative of negative ions adsorption or negative charge accumulation on the channel surface. Furthermore, the result represented that the nanoFET could detect the negative ions in air. The sensitivity of the device, $\Delta \mathrm{I} / \mathrm{I}_{\mathrm{o}}$, reaches to be over 700 . The $I_{\mathrm{ds}}$ increasing rate versus time, which is the slope of the $\mathrm{I}_{\mathrm{ds}}$ versus time, is approximately $80 \mathrm{nS} / \mathrm{sec}$ at the maximum.

For the numerical calculation of the number of adsorbed negative charges on the sensing area, metal-oxide-

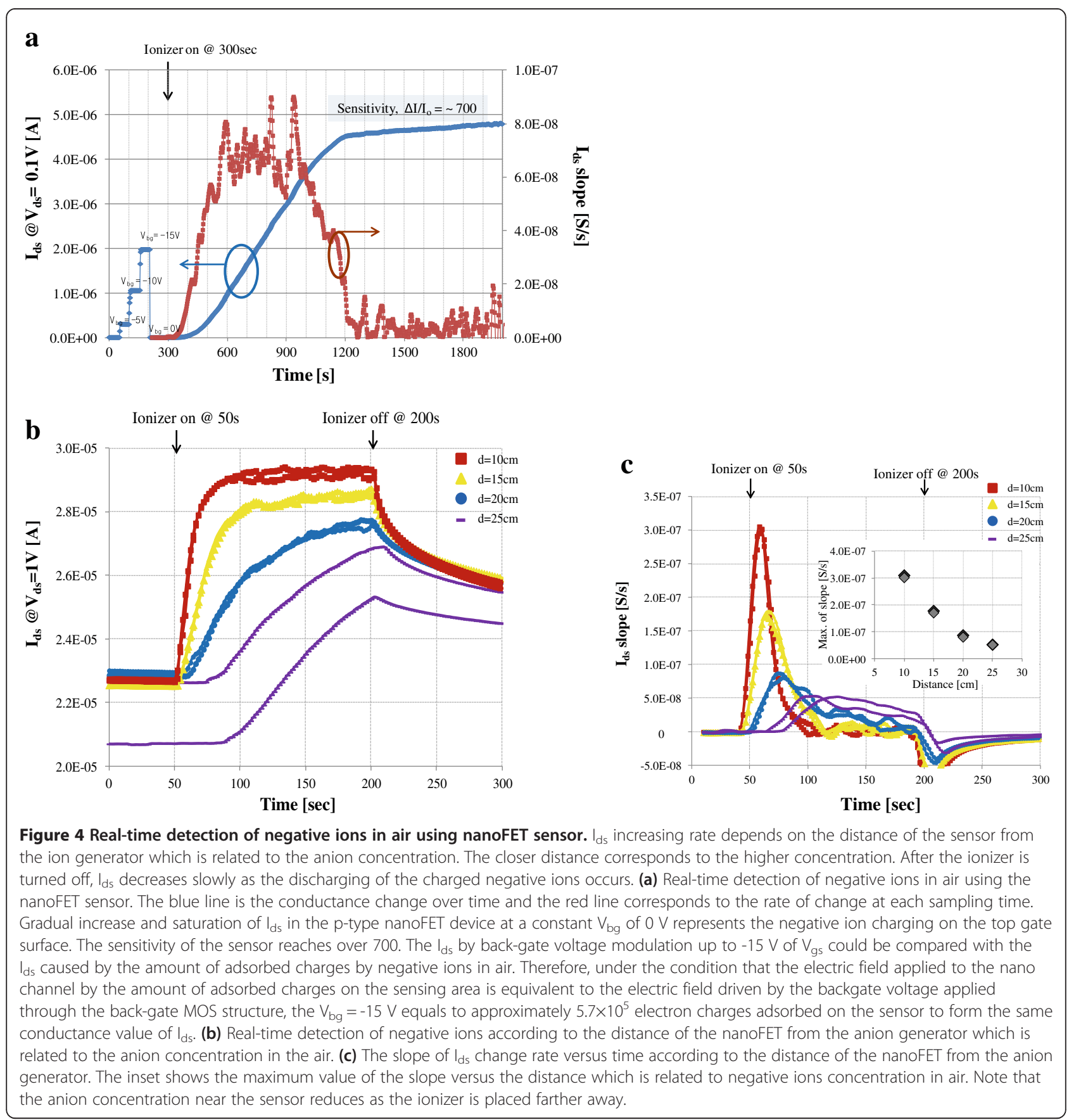


semiconductor (MOS) capacitance calculation is utilized. The nano silicon channel contacts two parallel plate MOS capacitors on the top and bottom of the channel, the top capacitor comprising of the gate oxide and sensing area and the bottom capacitor comprising of the BOX insulator and back-gate silicon substrate. Assuming the electric field applied to the nano silicon channel through both the top and bottom MOS capacitor is equivalent, in other words the $\mathrm{I}_{\mathrm{ds}}$ obtained by the adsorbed negative ions on the sensor is of equal or similar level to the $\mathrm{I}_{\mathrm{ds}}$ obtained by back-gate bias potential, then, the charges can be calculated using the following equation:

$$
\mathrm{Q}_{\mathrm{bg}}=\mathrm{C}_{\mathrm{box}} \mathrm{V}_{\mathrm{bg}}
$$

where, $\mathrm{C}_{\mathrm{box}}$ is the capacitance of BOX layer and $\mathrm{V}_{\mathrm{bg}}$ is the applied back-gate voltage. Under the experimental conditions when the conductance level, $\mathrm{I}_{\mathrm{ds}}$, of the nanochannel by the applied back-gate voltage is equal or similar to that by the electric field formed by the amount of the adsorbed charges on the sensing area of the top capacitor, then the adsorbed charges, $\mathrm{Q}$, equals to $\mathrm{Q}_{\mathrm{bg}}$. Therefore, since $C_{b o x}=6.1 \times 10^{-15}$ Farad, $V_{b g}=15 \mathrm{~V}$, then, $\mathrm{Q}=9.15 \times 10^{-14} \mathrm{C}=5.7 \times 10^{5}$ charges. The ionizer is known to generate the anions at a rate of approximately $2 \times 10^{6}$ ea./cc at $5 \mathrm{~cm}$ away from the ionizer. Since the amount of adsorbed charges is proportional to adsorption coefficient $\alpha$ and ion concentration in air $D$, then the adsorbed charges on the sensing channel $Q=\alpha D$. The coefficient $\alpha$ is 1 at the maximum, confirming that the numerical calculation using the experimental result is reasonable.

Figure 4(b) shows the result of quantitative detection of negative ions using the nanoFET. In order to confirm the feasibility of quantitative detection of the air ion concentration, the response of the nanoFET to the different ion concentration in air was measured. The air anion concentration was differentiated by varying the distance of the sensor to the ionizer as shown in Figure 2 (b). After the ionizer was turned on at $t=50 \mathrm{sec}$, the $\mathrm{I}_{\mathrm{ds}}$ responses increased, but showed different delay times depending on the ionizer position. This was due to the increase in time for the generated anions to reach the sensor. The distance between ion generator and nano FET sensor was set to 4 different positions from $25 \mathrm{~cm}$ to $10 \mathrm{~cm}$ in decreasing order. The results are represented by a dashed line and lines with circle, triangle, and rectangle markers, respectively, as shown in Figure 4 (b) and (c). In Figure 4(b), the slope of $\mathrm{I}_{\mathrm{ds}}$ before saturation was larger as larger amounts of negative ions reached the sensor at closer distances. Figure 4(c) shows the plot of the change rate of the slope of $I_{d s}$ at each sampling time. The measurement of air anion detection was repeated twice at each ionizer position. When the initial level of $I_{d s}$ for the measurement was of similar value, near $22.5 \mu \mathrm{A}$ then, the plot nearly overlapped, which indicated that the measurement results would be reproducible if the initial level of $\mathrm{I}_{\mathrm{ds}}$ is in the same condition. The slope of the $I_{d s}$ increasing rate produces the same peak value even with different initial levels of $\mathrm{I}_{\mathrm{ds}}$ as shown in Figure 4(c) and the inset. The inset of Figure 4(c) shows the maximum value of the slope versus the distance which is related to concentration of negative ions in the air. Note that the anion concentration near the nanoFET sensor reduces as the ionizer is placed at farther distances, which corresponds with the experimental measurement results. The initial $\mathrm{I}_{\mathrm{ds}}$ level cannot be controlled actively for the consecutive measurements because of the variable amount of adsorbed negative ions remaining on the channel surface which reduces gradually over time. However, even in this case, the quantitative detection of air anions using the nanoFET sensor may be possible because the increasing rates of $\mathrm{I}_{\mathrm{ds}}$ are related to the ion concentration. The measurement of $\mathrm{I}_{\mathrm{ds}}$ change rate for the quantification and calibration of the concentration of the immobilized negatively charged biomolecules on the channel, such as proteins in liquid solutions, was already demonstrated by the M. Reed group in Yale University $[17,19]$. They showed the possibility of quantification of the concentration of the charged protein molecules in liquid solution, but did not report an application with repeatable consecutive measurements. After the ionizer was turned off at $t=200 \mathrm{sec}, I_{d s}$ decreased due to the reduction of adsorbed negative ions on the channel as shown in Figure 4(b). This corresponded to the result described above and in Figure 3. The results of the experiment showed that the nanoFET sensor could detect negative ions in air quantitatively and the concentration could be analyzed by the slope of the channel conductance change rate during a real-time measurement. However, the initial, so-called 'ready', level of $\mathrm{I}_{\mathrm{ds}}$ for the air ion measurement was not actively controllable and was too slow to recover to the initial state after a measurement due to the residual charge caused by the adsorbed negative ions on the nanoFET channel surface. More experiments on sensor performance are required to verify the capability of reproducible quantitative measurements of air anions utilizing the nanoFET. These properties are essential for the commercialization of nanoFET device as an air anion detection sensor.

\section{Conclusion}

In this paper, we have characterized the response of the developed nanoFET sensor to the concentration of negative ions in air. We demonstrated the quantitative detection of negative ions in air during real-time measurement. The 
fabricated nanoFET showed the high performance characteristics of the p-type field-effect transistor. The nanoFET could detect and differentiate the concentration of negative ions in air generated by the ionizer indicated by the slope of the channel conductance change rate which was proportional to the ion concentration. From the experimental results, the conductance change of nanoFET channel was shown to be related with the anion concentration in the air. Furthermore, it was observed that the conductance of $\mathrm{I}_{\mathrm{ds}}$ decreased after reaching its saturation level in a resting state when the ion generator was turned off. Further research is underway to evaluate the limit of detection and dynamic range to differentiate the air anion concentration, and evaluate characteristics of reliability and reproducibility of the nanoFET anion sensor for commercialization.

\section{Competing interests}

The authors declare that they have no competing interests.

\section{Authors' contributions}

YT designed the nanoFET device and did the experiment and drafted the manuscript. KN brought the ideas and designed the concept and experimental setup. $\mathrm{KJ}$ performed analysis of the result. MH, HS, WK and YK discussed the experimental result. All authors read and approved the final manuscript.

\section{Acknowledgements}

This work was financially supported by the research fund of Ministry of Trade, Industry and Energy (MOTIE), Korea.

Received: 9 June 2014 Accepted: 6 August 2014

Published online: 15 August 2014

\section{References}

1. Krueger AP, Reed EJ (1976) Biological Impact of Small Air lons. Science 193:1209-1213

2. Sulman F (1983) The impact of weather on human health. Rev Environ Health 4:83-119

3. Horrak U, Salm J, Tammet H (2000) "Statistical characterization of air ion mobility spectra at Tahkuse Observatory: Classification of air ions,". Journal of Geophysical Research: Atmospheres (1984-2012) 105:9291-9302

4. Kreuger A, Smith RF (1960) The biological mechanisms of air ion action. J Gen Physiol 43:60

5. Blatny JM, Reif BAP, Skogan G, Andreassen O, Høiby EA, Ask E, Waagen V, Aanonsen D, Aaberge IS, Caugant DA (2008) Tracking airborne Legionella and Legionella pneumophila at a biological treatment plant. Environ Sci Technol 42:7360-7367

6. Fletcher LA, Gaunt LF, Beggs CB, Shepherd SJ, Sleigh PA, Noakes CJ, Kerr KG, (2007) Bactericidal action of positive and negative ions in air. BMC Microbiol $7: 32$

7. English J (2013) The Positive Health Benefits of Negative Ions. Nutri Rev

8. Kosenko EA, Kaminsky YG, Stavrovskaya IG, Sirota TV, Kondrashova MN (1997) The stimulatory effect of negative air ions and hydrogen peroxide on the activity of superoxide dismutase. Febs Letters 410:309-312

9. Livanova L, Levshina I, Nozdracheva L, Elbakidze M, Airapetyants M (1999) The protective effects of negative air ions in acute stress in rats with different typological behavioral characteristics. Neurosci Behav Physiol 29:393-395

10. Reilly T, Stevenson I (1993) An investigation of the effects of negative air ions on responses to submaximal exercise at different times of day. J Hum Ergol 22:1-9

11. Kim YS, Yoon KY, Park JH, Hwang J (2011) Application of air ions for bacterial de-colonization in air filters contaminated by aerosolized bacteria. Science of the total environment 409:748-755

12. Park CW, Park JW, Lee SH, Hwang J (2014) Real-time monitoring of bioaerosols via cell-lysis by air ion and ATP bioluminescence detection. Biosens Bioelectron 52:379-383
13. Geiger H, Müller W (1928) Elektronenzählrohr zur messung schwächster aktivitäten. Naturwissenschaften 16:617-618

14. Shinohara N, Tokumura M, Kazama M, Yoshino H, Ochiai S, Mizukoshi A (2013) Indoor air quality, air exchange rates, and radioactivity in new built temporary houses following the Great East Japan Earthquake in Minamisoma, Fukushima. Indoor Air 23:332-341

15. Noras MA, Williams BT, Kieres J (2005) A novel ion monitoring device. Journal of electrostatics 63:533-538

16. Elfstrom N, Karlstrom AE, Linnrost J (2008) Silicon nanoribbons for electrical detection of biomolecules. Nano Lett 8:945-949

17. Stern E, Vacic A, Rajan NK, Criscione JM, Park J, llic BR, Mooney DJ, Reed MA, Fahmy TM (2010) Label-free biomarker detection from whole blood. Nat Nanotechnol 5:138-142

18. Fletcher L, Noakes C, Sleigh P, Beggs C, Shepherd S (2008) Air ion behavior in ventilated rooms. Indoor and Built Environment 17:173-182

19. Vacic A, Criscione JM, Stern E, Rajan NK, Fahmy T, Reed MA (2011) Multiplexed SOI BioFETs. Biosens Bioelectron 28:239-242

doi:10.1186/s40486-014-0007-6

Cite this article as: Seo et al:: Negative ions detection in air using nano field-effect-transistor (nanoFET). Micro and Nano Systems Letters 2014 2:7.

\section{Submit your manuscript to a SpringerOpen ${ }^{\circ}$ journal and benefit from:}

- Convenient online submission

- Rigorous peer review

- Immediate publication on acceptance

- Open access: articles freely available online

- High visibility within the field

- Retaining the copyright to your article

Submit your next manuscript at $\gg$ springeropen.com 